\title{
O SILÊNCIO DA EDUCAÇÃO AMBIENTAL NA BASE NACIONAL COMUM CURRICULAR: UMA ANÁLISE DO EFEITO DE DESLIZAMENTO SOFRI- DO PELO TERMO NA BNCC
}

\begin{abstract}
THE SILENCE OF ENVIRONMENTAL EDUCATION IN THE COMMON NATIONAL CURRICULAR BASIS: AN ANALYSIS OF THE SLIP EFFECT SUFFERED BY THE TERM IN THE BNCC
\end{abstract}

Ana Josefina Ferrari ${ }^{1}$

Elaine Trindade de Oliveira Ribeiro ${ }^{2}$

\begin{abstract}
Resumo
A temática desenvolvida neste artigo, o silenciamento da Educação Ambiental (EA) na Base Nacional Comum Curricular, é resultado parcial de uma investigação desenvolvida durante o mestrado. A metodologia que orientou aquela pesquisa foi de caráter documental e bibliográfica, com abordagem qualitativa. A mesma partiu da necessidade em saber, onde, no texto da BNCC, documento base para a reformulação dos currículos escolares, estaria contemplada a EA. A pesquisa esteve fundamentada em autores que se ocuparam em explicitar a importância da EA e autores da Análise de Discurso francesa, alguns dos quais traremos no presente artigo. Verificamos que o tema da EA, no documento normativo da BNCC, não é mencionado, ficando o mesmo restrito ao quarenta por cento de conteúdo diversificado a ser tratado nos currículos escolares de acordo promulgado na Lei de Diretrizes e Bases (LDB). Por fim, se percebeu um deslizamento de sentido, como denomina a Análise do Discurso francesa, sofrido pelo termo EA nos conteúdos comuns da BNCC, produzindo um efeito de silenciamento do termo EA e sua problemática. Desse modo, o objetivo do presente artigo é apresentar tanto a análise feita do termo Educação Ambiental no texto da BNCC quanto as análises que mostram o deslizamento de sentido que o termo EA sofre nas diferentes sequencias da normativa. A questão que se coloca é saber a que sujeitos interessa o silenciamento de debates e reflexões críticas nos currículos escolares, de temáticas tão importantes e urgentes?
\end{abstract}

Palavra-chave: Base Nacional Comum Curricular; Bem Viver e Educação; Educação Ambiental Crítica.

\begin{abstract}
The theme developed in this article, the silencing of Environmental Education (EA) in the National Common Curriculum Base, is the partial result of an investigation developed during the master's degree. The methodology that guided this research was documentary and bibliographic, with a qualitative
\end{abstract}

\footnotetext{
* Artigo Original: Recebido em 18/10/2021 - Aprovado em 05/11/2021.

${ }^{1}$ Professora do Curso de Licenciatura em Linguagem e Comunicaçãoe do Programa de Pós-Graduação em Rede Nacional para o Ensino das Ciências Ambientais (Profciamb), Universidade Federal do Paraná, Setor Litoral (UFPR Litoral), Matinhos/PR, Brasil.e-mail: ana.josefina@gmail.com Orcid https://orcid.org/0000-0002-9273-7709

${ }^{2}$ Professora da rede Estadual do Mato Grosso, Mestra em Ensino das Ciências Ambientais, Pedagoga parceria FAEL-UNISA/ SP, Especialização em Educação Infantil e Séries Iniciais pela EADCON e Gestão Escolar, pela Faculdade São Braz, Profciamb, Matinhos/PR, Brasil.e-mail: etonbmt@gmail.com Orcid https://orcid.org/0000-0002-2703-2665
} 
approach. It started from the need to know, where, in the text of the BNCC, the basic document for the reformulation of school curricula, the EA would be contemplated. The research was based on authors who were involved in explaining the importance of AS and authors of the French Discourse Analysis, some of whom we will bring in this article. We verified that the theme of The EA, in the bncc normative document, is not mentioned, being the same restricted to forty percent of diversified content to be treated in school curricula according to promulgated in the Law of Guidelines and Bases (LDB). Finally, a slip of meaning was perceived, as the French Discourse Analysis is called, suffered by the term EA in the common contents of the BNCC, producing a silencing effect of the term EA and its problematic. Thus, the aim of this article is to present both the analysis made of the term Environmental Education in the text of the BNCC and the analyses that show the meaning slip that the term EA suffers in the different sequences of the normative. The question is to know which subjects are interested in the silencing of debates and critical reflections in school curricula, of such important and urgent topics?

Keyword: Common National Curriculum Base; Well Living and Education; Critical Environmental Education.

\section{Relação sociedade e natureza: à guisa de introdução}

O presente artigo apresenta uma parte da análise do termo Educação Ambiental (EA) na Base Nacional Comum Curricular (BNCC) realizada na dissertação de mestrado, a qual foi defendida no programa de mestrado PROFCIAMB da UFPR. Procuramos mostrar aqui, o deslizamento de sentido, como denomina a Análise do Discurso (AD) francesa, que, por efeito metafórico produz um efeito de silenciamento do termo EA na normativa mencionada. A pesquisa, inicialmente, partiu da constatação de mudanças, promovidas pela normativa BNCC (Brasil; 2018), do status da EA na Educação básica. Este fato despertou a curiosidade das autoras no que se refere ao tema.

Desse modo, no texto da dissertação de mestrado defendida, com o objetivo analisar o termo "Educação Ambiental", vários autores foram consultados. A pesquisa realizada foi de caráter documental e bibliográfica, com abordagem qualitativa. Desse modo, Acosta e Breda (2016); Dussel (2018); Diamond (2005; Quijano (2009), que são autores que discutem a problemática da relação do ser humano com a natureza e sua repercussão na sociedade, foram estudados e Orlandi (2007; 2015); Silva (2012) e Ferrari (2008) que trabalham dentro da Análise de Discurso francesa também foram pesquisados. As contribuições teórico-conceituais deles, a partir de uma revisão do pensamento filosófico de cada um e considerando o momento histórico em que estavam inseridos, nos ofereceram momentos de questionamentos e reflexões, sobre o pensamento vigente na época da produção da BNCC e sobre a nossa relação e conexão do ser humano com a Natureza.

Para Acosta e Breda (2016), urge superar o divórcio entre a Natureza e o ser humano. “[...] a relação com a Natureza é essencial na construção do Bem Viver" (ACOSTA; BREDA, 2016, p. 28). Essa mudança histórica e civilizatória é o maior desafio da Humanidade, se é que não se deseja colocar em risco nossa própria existência. Fazer reflexões sobre essa desconexão é de suma importância. É preciso pensar sobre como o ser humano se relaciona com o meio em que vive e sobre o quanto suas ações vêm alterando negativamente a natureza. Desse modo, é preciso compreender o conceito de natureza, resgatando o pensamento de pertencimento e unidade com ela, buscando, assim, o equilíbrio na relação ser humano, sociedade e natureza. Contudo verificamos que, para além dessa leitura de superfície, o texto clamava por outra forma de abordagem. No momento da pesquisa que aqui trazemos, impôs-se a necessidade de pensar a língua enquanto forma material e que isso pressupõe compreendê-la como opaca, reconhecendo a necessidade de identificar a manobra linguística utilizada para provocar o "silenciamento" do termo EA a partir dum processo gradativo de deslocamento via metáfora. A análise, então, valeu-se de elementos da Análise do Discurso (AD) para observar os efeitos de sentido produzidos pelo texto da normativa. Observamos, portanto, o lugar de conflito entre 
diferentes redes de significação para identificar os deslizamentos de sentido sofridos pelo termo EA.

Muitos autores, ao longo da história, ocuparam-se da questão da relação do ser humano com a natureza. O livro "Pensar o Ambiente: bases filosóficas para a Educação Ambiental”, em parceria com a UNESCO, organização de Carvalho, Grün e Trajber (2006), apresenta diferentes autores que se ocuparam do tema e escreveram a respeito desta relação sob diversas perspectivas. No livro: "Os (des)caminhos do meio ambiente" Carlos Walter Porto Gonçalves (2005) realiza uma breve contextualização das condições histórico-culturais das quais emerge o movimento ecológico, onde cada povo/cultura, constrói seu conceito de natureza e juntamente a isso compõe as suas relações sociais. Na América Latina surgiram, nas últimas décadas, propostas de mudanças no comportamento da sociedade. No livro “O Bem Viver” (ACOSTA; BREDA, 2016), um dos maiores responsáveis por colocar Direitos da Natureza na Constituição do Equador, tem como objetivo explicar o conceito do Bem Viver e também, fazer um alerta a todos os leitores, relatando que o mundo precisa de mudanças radicais e que o ser humano necessita de outras formas de organização social e práticas políticas.

Enrique Dussel (2018), filósofo argentino, afirma que o ser humano, dito moderno, traz consigo características e pensamentos eurocêntricos, e apresenta um projeto de vida diferente, ou seja, não é o mesmo projeto de vida dos povos originários da América. Se comparamos o tipo de vida dos povos originários com a vida do ser humano moderno, veremos que o ser humano moderno perde a conexão com a natureza quando não tem mais contato com plantas, jardins, com o lugar, e que vive em meio ao cimento e à construção, apresentando um projeto de vida muito particular, próprio do ser humano moderno. Fazer reflexões sobre essa desconexão é de suma importância, ou seja, pensar sobre como o ser humano se relaciona com o meio em que vive e sobre o quanto suas ações vêm alterando negativamente a natureza. Compreender o conceito de natureza, resgatando o pensamento de pertencimento e unidade com ela, buscando, assim, o equilíbrio na relação ser humano, sociedade e natureza, é fundamental.

Tratando ainda sobre o tema, Jared Mason Diamond (2005, no livro COLAPSO apresenta como as sociedades escolhem o fracasso ou o sucesso de seus modos de vida. Para Diamond (2005, p. 25),
"Os povos antigos não eram nem maus gestores ignorantes que merecessem ser exterminados ou espoliados, nem ambientalistas conscientes que resolviam problemas que não podemos resolver hoje". Eram indivíduos como nós, com adversidades, em muito, semelhantes às que hoje enfrentamos. Tinham tendência quer para o êxito, quer para o fracasso, em conjunturas semelhantes àquelas que nos fazem prosperar ou falhar. É verdade que há diferenças entre as situações com as quais nos defrontamos hoje e aquelas em que viviam os povos antigos, mas ainda há semelhanças suficientes para que possamos aprender com o passado. Desse modo, observamos que a relação do ser humano com o espaço que o rodeia está atravessada por uma categoria denominada trabalho.

\section{Ser humano, trabalho e a sua própria natureza}

Há uma singularidade orgânica na relação entre o ser humano e a natureza, e, nessa relação, ambos têm vivenciado uma série de situações, as quais traduzem o modo de relacionamento mútuo. Como já observamos acima, ao longo da história humana, a natureza tem sido concebida sob diversos pontos de vista. O modo de pensar a natureza passou pela contemplação de deuses, depois pela ciência e pelas técnicas, e pelo pensamento dicotomizado, que gera a separação natureza-sociedade (cultura-natureza, história-natureza), que é uma característica marcante do pensamento de dominação do mundo ocidental, cuja matriz filosófica se encontra na Grécia e na Roma clássicas. Para Gonçalves (2005), a afirmação dessa oposição se deu na complexa História do Ocidente, em lutas e práticas sociais.

Tozoni-Reis e Maia, (2014), citam Marx, que diz que esta atividade essencial humana de interferência e de transformação da natureza é chamada de trabalho.

Os homens transformam a natureza, produzindo seus meios de vida, determinando indiretamente a sua vida material: suas necessidades criam novas necessidades, produzindo o gênero humano, a cultura humana. Esta atividade vital humana de intervenção e modificação da natureza é chamada de trabalho: “(...) um processo entre o ser humano e a natureza, (...) no qual o ser humano media, regula e controla 
pela sua própria ação seu metabolismo com a natureza (TOZONI-REIS; MAIA, 2014, p. 93).

A necessidade para os homens de estabelecer outra relação com a natureza física, que lhes cabe dominar e manejar em seu proveito. De acordo com TozoniReis e Maia (2014)

Os processos humanos no atual modo de produção interferem diretamente na regulação biológica natural. Isso se deve a que o ser humano para existir precisa modificar o ambiente a sua volta, em outras palavras, ele vale-se de seu potencial para modificar as condições do meio de forma a possibilitar seu acesso aos bens naturais transformandoos, por meio do seu trabalho, em produtos importantes para a sociedade (TOZONI-REIS; MAIA, 2014, p. 26).

Por meio do trabalho, o ser humano vem transformando e modificando recursos da natureza, produzindo objetos úteis à vida humana, em prol de sua própria sobrevivência e/ou manutenção econômica de uma sociedade. Nessa relação o ser humano vem intensificando sua dominação e os processos de produção, alterando de forma significativa os elementos da natureza e o meio que vive. No processo de apropriação e de transformação dos recursos pelo ser humano, através do trabalho, ocorre o processo de socialização da natureza e o desenvolvimento das sociedades fez com que o ser humano moderno e ocidental passasse a acreditar que toda natureza poderia ser submetida ao seu domínio e a sua exploração.

No livro "Educação ambiental a várias mãos: educação escolar, currículo e políticas públicas", organização: Marília Freitas de Campos Tozoni-Reis, Jorge Sobral da Silva Maia (2014), os autores relatam que o ser humano, ao longo da história, sempre adotou um modo de produção que seja "comunal, escravista, feudal ou capitalista, e interferiu nos ciclos naturais. À medida que aprimorava seus instrumentos e potencializava sua capacidade de intervenção no meio, mais se apropriava da natureza e mais a transformava para si”:
[...] e que nos dias de hoje na forma mais intensa de ação do modo produção capitalista: a exploração do trabalho alheio que produz riqueza. Tem-se então a divisão da sociedade em classes e o advento da propriedade privada: de um lado os donos dos meios de produção e de outro os trabalhadores. "Estes últimos vendem sua mão de obra em troca de salários que lhes garantirão sua sobrevivência e de seus familiares, em contrapartida, o produto de seu trabalho não lhes pertence, mas ao dono dos meios de produção". [...] relação de exploração tem por base a obtenção do lucro e acumulação de bens a partir da expropriação do trabalhador e a máxima exploração dos bens naturais na produção das mercadorias. Esse modelo, em linhas gerais, causa os diversos problemas socioambientais [...] (TOZONI-REIS; MAIA, 2014, p. 26-27).

Loureiro e Torres (2014), ao interpretar Freire, explicam que seus escritos possibilitam, entre muitos aprendizados, o entendimento de que:

[...] é pelo trabalho que se supre as necessidades de sobrevivência e nos constituímos socialmente, e é nessa relação que se transforma a própria natureza. Visto assim é elemento ontologicamente fundante do ser social, gerador, pela sua capacidade de modificar a realidade objetiva, o que permite compreender as relações entre história humana e a natureza modificada como especificidade da natureza humana (LOUREIRO; TORRES, 2014, p. 160).

No que se refere ao atual desenvolvimento do modo de produção capitalista observamos que este caminha para uma produção destrutiva, assim, é preciso refletir sobre o processo de transformação da natureza realizado pelo ser humano por meio 
do trabalho. Pois se entendermos que o ser humano também é natureza, compreendemos que, à medida que destrói os recursos naturais, o ele caminha para sua autodestruição, comprometendo, assim, o seu modo de vida e as gerações futuras e até mesmo a existência da própria humanidade. Por isso, é importante compreender o processo histórico para que possamos contribuir na formulação de conceitos de natureza na sociedade contemporânea e, assim, compreender o modo de agir, pensar, produzir e viver dessa sociedade. Desse modo, o trabalho estará presente em qualquer sociedade, porém o que muda é a forma como se configura em cada sociedade ao longo da história. Estes temas são imprescindíveis para nossa sociedade hoje e deveriam ser tratados na escolas, discutindo com nossos estudantes estas problemáticas.

\section{0 (des)envolvimento na relação ser humano- natureza}

O ser humano gerou muitas formas de interação com a natureza, desde uma interação de unidade à segregação. Ao percorrer o processo histórico, percebe-se que essa interação perpassou e perpassa por situações variadas de interdependência, transformação, destruição, exploração, construção e evolução. Um exemplo de desenvolvimento são as catástrofes naturais, como, por exemplo, as secas e inundações, terremotos e maremotos, entre outros. Outro exemplo são as relações que dizem respeito às formas pelas quais as ações humanas transformam o meio natural e utilizam-se deste para o seu "desenvolvimento". O fortalecimento das ações do ser humano na natureza e seu poder de intervenção são perceptíveis em vários momentos da história, desde a pedra lascada até os nossos dias.

As sociedades vêm propondo técnicas e, consequentemente, produzindo transformações, cada vez mais avançadas no meio natural. E, ao aprimorar essas técnicas, gerando um maior poder de exploração, construção e transformação do espaço geográfico, causam, consequentemente, maiores impactos sobre a natureza. Portanto, essa relação de desequilíbrio entre o ser humano e o meio natural na busca pelo (des)envolvimento, numa relação artificial, tem provocado e acelerado impactos ambientais. Lembremos que a natureza é orgânica e ela também gera impactos sobre a sociedade. Esse prisma é de necessária compreensão para que não se considere o espaço natural como um meio estático, passivo, sem ação.

Como já alertava o geógrafo, escritor, cientista, jornalista, advogado e professor universitário brasileiro, Milton Almeida dos Santos, no livro "A Natureza do Espaço: Técnica e Tempo, Razão e Emoção" (SANTOS, 2006), o conceito de espaço geográfico está associado à evolução das técnicas e à mudança da relação sociedade-natureza. Nessa relação o meio natural, ou seja, dado pela natureza, vem sendo substituído por relações artificializadas. Nessa perspectiva, o autor indica que: "podemos admitir que a história do meio geográfico pode ser grosseiramente dividida em três etapas: o meio natural, o meio técnico, o meio técnico-científicoinformacional" (SANTOS, 2006, p. 156).

$\mathrm{Na}$ primeira etapa, anterior às máquinas, o ser humano escolhia da natureza as partes ou aspectos considerados fundamentais à sua vida. Nesse período, havia uma relação harmoniosa e de respeito com a natureza; na segunda etapa: período técnico, espaço mecanizado, novos tempos sociais, da fabricação das máquinas, a intensificação da produção, uma nova forma de intercâmbio. "[...] o ser humano mudando a Natureza, impondo-lhe leis [...]”, prevalecendo a razão do comércio e não a razão da natureza; na terceira etapa, inicia uma profunda interação da ciência e da técnica, os objetos são elaborados a partir dos mandamentos da ciência. De acordo com Santos (2006):

Essa união entre técnica e ciência vai dar-se sob a égide do mercado. E o mercado, graças exatamente à ciência e à técnica, torna-se um mercado global. A ideia de ciência, a ideia de tecnologia e a ideia de mercado global devem ser encaradas conjuntamente e desse modo podem oferecer uma nova interpretação à questão ecológica, já que as mudanças que ocorrem na natureza também se subordinam a essa lógica [...] (SANTOS, 2006, p. 159).

E, nessa lógica, a aceleração das relações predatórias entre o ser humano e o meio, impõem mudanças radicais à natureza gerando crise ecológica. 
No artigo intitulado "Educação Ambiental: A educação para o consumo na sociedade da informação", Telma Domingues da Silva (2012), aborda a temática da educação ambiental "tendo em vista a discursividade da "responsabilidade socioambiental", como parte de um conjunto maior de discursos que configurariam as práticas de "educação ambiental" presentes hoje para a formação do cidadão enquanto cidadão mundializado" (SILVA, 2012 p. 563). Busca-se, no artigo, uma conexão com a discursividade presente na escolarização do tema, ou seja, como a educação ambiental é abordada pela escola e como se apresenta nos documentos oficiais, assim como quais as contribuições da escola para a formação desse "cidadão mundializado" (SILVA, 2012, p. 566). O corpus de análise da autora são as embalagens de produtos que se apresentam como produto com responsabilidade socioambiental e como a indústria da propaganda investe em não só definir o perfil do consumidor como e mesmo antes disso definir as estratégias de fazê-lo pensar que é uma escolha sua, de consumidor, quando, na realidade, ele é alvo de toda uma logística de convencimento.

O trabalho de Silva (2012, p. 563) é fundamentado nas ideias de autores como Pêcheux e Orlandi, e detecta claramente onde a teoria da Análise de Discurso oferece uma radiografia do sujeito que se transforma em objeto, imaginando, ainda, ser sujeito de suas escolhas. Conforme Silva (2012, p. 564) “em uma sociedade como a nossa, o sujeito urbano é o corpo em que o capital está investido. Nesse espaço definido pela memória, a história se faz por um 'eu' que é urbano".

A autora ressalta que, na sociedade atual, a televisão atuou como o veículo de comunicação de massa, e afirma também que hoje o termo foi aprimorado para "sociedade de informação", uma vez que é necessário construir essa ideia de que ser de massa esvazia a possibilidade de se ter autonomia de escolha, isso influenciado também pelo advento da internet. Assim, a mídia empenhou-se em criar a figura do cidadão consciente de escolhas sustentáveis, por meio de uma educação ambiental com "paradigma do naturalismo, que representou, entre as décadas de 1960 e 1970" (SILVA, 2012 p. $565)$, ou seja, voltada a fidelizar um cliente para o produto e não necessariamente para as questões ambientalistas, pelo bem do planeta. A importância do tratamento da problemática o encontramos com Silva (2012). A partir das contribuições da autora podemos observar, já desde uma perspectiva crítica, o texto da BNCC e os deslizamentos de sentido que sofre o termo EA.

A sociedade contemporânea tem vivenciado um desenvolvimento tecnológico bastante expressivo e vem provocando (Des)envolvimento na relação ser humano/natureza. $\mathrm{Na}$ análise da palavra desenvolvimento e sua influência na sociedade contemporânea é possível perceber que, com a junção dos elementos que compõem a palavra desenvolvimento, formaremos algo que poderia ser expresso como: "sem movimento para reverter a ação" ou ainda "sem envolvimento". Isso nos remete a uma conclusão de que é preciso algo para gerar o movimento e/ou envolvimento. Para o Aníbal Quijano (2009, p. 139), sociólogo peruano, em seu artigo "El fantasma del desarrollo en América Latina", o autor escreve que foi depois da "Segunda Guerra Mundial que surgiu o termo desenvolvimento, entendido por algumas pessoas como uma fase posterior do subdesenvolvimento [...]". No caráter eurocêntrico, foi uma expressão da reconfiguração do capitalismo mundial. Para Quijano (2009, p. 140), “Desenvolvimento, é um termo de biografia perigosa na América Latina. Desde a Segunda Guerra Mundial mudou muitas vezes de identidade e sobrenome". Acosta e Breda (2016, p. 48), ao citar Quijano apontam que: o termo desenvolvimento, "como toda crença, nunca foi questionado: foi simplesmente redefinido por suas características mais definidas". Assim, os autores explicam que diferenciá-lo do que nos apresenta o ser humano que atribui sobrenomes à palavra desenvolvimento: "desenvolvimento econômico, desenvolvimento social, desenvolvimento local, desenvolvimento global, desenvolvimento rural, desenvolvimento sustentável, ecodesenvolvimento, etnodesenvolvimento, subdesenvolvimento [...]". Algumas destas expressões são as que encontramos no texto da BNCC ocupando o lugar da Educação ambiental como veremos no próximo ponto.

\section{Análise do efeito de deslizamento sofrido pelo termo "educação ambiental" no texto da BNCC}

Para a análise do corpus do documento BNCC e conclusão da pesquisa foram utilizadas as obras de Eni P. Orlandi (2015), "Análise de Discurso: princípios e procedimentos" e "As formas do silêncio: no movimento dos sentidos" (ORLANDI, 
2007) e FERRARI (2008; 2017). Na vertente francesa, as autoras oferecem contribuições sobre as possibilidades de observar, no texto da normativa, os diversos discursos presentes e nos colocam em estado de reflexão sobre as possibilidades de abordagem do texto e de sua materialidade.

De acordo com Orlandi (2015), para a análise de um corpus, é preciso montar um dispositivo. A montagem consiste em diferentes etapas sucessivas que começam no texto, como unidade material e vão até a formação ideológica. Assim, para o desenvolvimento desta pesquisa, foi trabalhado, na primeira etapa, o que corresponde à passagem da superfície linguística para o objeto teórico discursivo. Para Orlandi (2015), nesta etapa “o analista, no contato com o texto procura ver nele sua discursividade". Neste momento, trabalhamos com a análise das paráfrases, ou seja, da relação do dizer e não dizer na busca do termo EA na materialidade do documento. Desse modo podemos observar os diferentes movimentos do sentido, seus deslizamentos, partindo do pressuposto de que o sentido não é fixo e que a língua não é transparente. O sentido se produz e é móvel.

A segunda etapa, que consiste na passagem do objeto teórico discursivo ao processo discursivo, por meio das formações discursivas que estão em jogo na produção dos sentidos. Neste momento, foram demarcando os jogos de sentido produzidos, observando os efeitos metafóricos e colocando em relação do discurso e a língua e analisando o modo de articulação e deslizamento de sentidos.

Na terceira etapa, ocorre a passagem das formações discursivas para as formações ideológicas, devido à inscrição do interdiscurso. Orlandi (2015), afirma que "a Análise de Discurso tem um procedimento chamado de ir-e-vir constante entre a teoria, consulta ao corpus e análise". E esse processo se dá ao longo da pesquisa, como se o analista fosse uma bordadeira, onde a linha, agulha, mãos e pano (se)produzem em uma relação conjunta, tecendo uma forma, desenhando uma figura. Assim, nesse movimento constante de interpretação o analista "tece as intrincadas relações do discurso, da língua, do sujeito, dos sentidos, articulando ideologia e inconsciente" (ORLANDI, 2015, p. 65).

Durante o procedimento analítico, é importante o analista observar os efeitos metafóricos. Falamos de metáfora não vista como desvio, mas sim como transferência, ou seja, outro modo de falar. Na representação proposta por Orlandi (2015), é possível observar o trabalho produzido pelo deslize e o efeito metafórico (Figura 1).

Figura 1 - Esquema de deslize (a deriva)

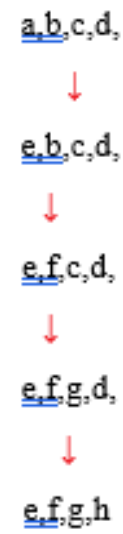

FONTE: Orlandi (2015, p. 77). 
Nessa representação, o ponto de partida é (a,b,c,d,) e o ponto de chegada é (e,f,g,h). Percebe-se que o dito nas formas/palavras, sofre um deslocamento. Este deslizamento leva a que a forma/palavra seja sempre outra, e elas podem significar de modos diferentes. As palavras mudam de sentido conforme lugar e tempo de enunciação e aqueles que as empregam. "As palavras falam com outras palavras. Toda palavra é sempre parte de um discurso. E todo discurso delineia na relação com os outros: dizeres presentes e dizeres que se alojam na memória" (ORLANDI, 2015, p. 41).

No trabalho de análise do corpus, em um primeiro momento, realizamos uma leitura da BNCC , especialmente do Caderno Ciências da Natureza (CCN), situado entre as páginas 321 e 351 (BRASIL 2018). Em seguida, procuramos mapear um conjunto de termos que consideramos formar parte do campo semântico da EA, anotando o número de vezes que ele aparecia no texto da BNCC (BRASIL 2018). Os termos procurados foram: Educação Ambiental, Meio Ambiente, Ambiente, Natural ou Naturais, Natureza, Recursos Naturais, Sustentabilidade, Socioambiental ou Socioambientais, Equilíbrio, Desequilíbrio e Desenvolvimento Sustentável, procurando encontrar a relação do ser humano com a natureza.

Foi observado que, embora os termos: ambiente, recursos naturais e sustentabilidade sejam palavras que nos remetem a pensar no campo semântico da educação ambiental, conforme demonstrado, o contexto de ocorrência no qual aparecem estas palavras, elas estão associadas à ideia de comportamento primitivo, no sentido de exploração e transformação do mundo natural.

Constatação importante é que o sentido do termo Educação Ambiental sofre um deslocamento, ou seja, o sentido do termo vai "deslizando", até nos remeter a outros sentidos produzindo outros efeitos (Figura 2).

Figura 2 - Esquema de deslize da palavra pelo efeito metafórico

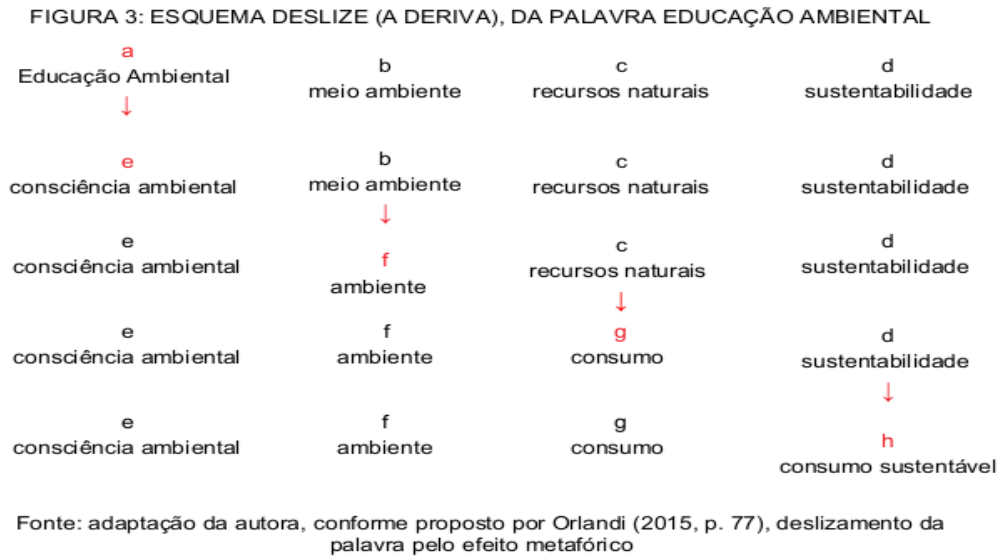

FONTE: Orlandi (2015. P. 77)

O deslizamento de sentidos se produz do termo Educação ambiental (mencionado na Introdução da BNCC a consumo sustentável (presente nos cadernos de Ciência da natureza da BNCC) (BRASIL 2018), produzindo uma passagem de uma Formação Discursiva Ambiental crítica a uma
Formação Discursiva relacionada ao pensamento Cartesiano Moderno.

O processo de produção de sentidos está sujeito ao deslize, havendo sempre um 'outro' possível que o constitui. Como dissemos, o deslize de a para e 
faz parte do sentido de a e de e. Tanto o diferente como o mesmo são produção da história, são afetados pelo efeito metafórico. (ORLANDI, 2015, p. 78).

Podemos dizer que na relação de sentidos na BNCC a Formação discursiva cartesiana se articulam formando um texto baseado numa ideia de ciência de uma ideologia moderna, uma modernidade como entende Quijano (2013): "Estamos, pois, imersos em um processo de completa reconfiguração da "Colonialidade" Global de Poder, o padrão de poder hegemônico no planeta. "Trata-se, em primeiro ponto, da aceleração e aprofundamento de uma tendência de reconcentração do controle do poder". Entre várias tendências centrais citadas pelo autor foi "a exacerbação da 'exploração da natureza";

[...] um dos elementos fundamentais da 'Colonialidade'/Modernidade/ Eurocentrada é o novo e radical dualismo cartesiano, que separa a "razão" e a "natureza". Dali, uma das ideias/imagens mais características do Eurocentrismo, em qualquer de suas vertentes: a "exploração da natureza" como algo que não requer justificação alguma e que se expressa cabalmente na ética produtiva engendrada junto com a "revolução industrial". Não é difícil perceber a inerente presença da ideia de "raça" como parte da "natureza", como explicação e justificação da exploração das "raças inferiores (QUIJANO, 2013, p. 46).

Orlandi (2007, p. 101), cita Certeau, 1980, no texto: "Uma política de silêncio", o qual afirma "já é bem conhecido que poder se exerce acompanhado de um certo silêncio". Ao observar a Figura 2 é possível perceber o deslize do termo EA no documento da Base que leva a outros sentidos e deixando um vazio, um silêncio que atravessa toda a normativa em todas as páginas seguintes da mesma.

Ao observar esta constatação também nos lembramos de Edgar Morin, em sua obra "Os sete saberes necessários à educação do futuro" (MORIN, 2011), onde aborda as questões centrais a serem consideradas para a educação no século XXI. O autor expõe que todas as escolas e todos educadores precisam se preocupar com a complexidade de entender o todo no processo do ensino aprendizagem, pois a sociedade é complexa, o ser humano é complexo, e que o ato educativo é complexo. Para Morin (2011), a educação do futuro deve se preocupar com a importância do conhecimento que deve aparecer como necessidade primeira e organizar um ensino aprendizagem voltado ao contexto global, o multidimensional.

O complexo voltado ao conhecimento do ser humano como parte do universo. Para ele, a educação para o futuro depende da união dos saberes, pois o que existe hoje é a total fragmentação, divisão, onde encontramos duas linhas de educação: de um lado, a escola ou os currículos divididos em partes, em disciplinas e, de outro lado, a vida, onde os problemas são cada vez mais multidisciplinares, globais e planetários. $\mathrm{O}$ autor afirma que é preciso "civilizar nossas teorias, ou seja, desenvolver nova geração de teorias abertas, racionais, críticas, reflexivas, autocríticas, aptas a se autorreformar". Estamos na era planetária, é preciso situar o "ser humano no universo", num pensamento de unidade e "não o separar dele" (MORIN, 2011, p. 32).

A educação está organizada num pensamento cartesiano, onde se separa o sujeito do objeto, ou seja, a filosofia e a pesquisa reflexiva de um lado e a ciência e a pesquisa objetiva do outro. Assim, a educação nos ensinou e continua nos ensinando a separar, a fragmentar e a isolar conhecimentos. Para Morin (2011, p. 39), "o saber disperso e compartimentado conduz à atrofia da disposição mental natural de contextualizar e de globalizar". Assim, "o enfraquecimento da percepção global conduz ao enfraquecimento da responsabilidade (cada qual tende ser responsável apenas por sua tarefa especializada), assim como ao enfraquecimento da solidariedade (cada qual não mais sente os vínculos com seus concidadãos)".

Com ensino das Ciências desconectado das outras ciências, com uma base que, em seu discurso, apresenta um ensino padronizado, onde prioriza a base-comum, preparando alunos para exames, provas externas e apresenta um silenciamento na parte diversificada, tanto que só é mencionada uma vez, fica o questionamento sobre que modelo de sociedade poderá se formar? Modelo de concorrência onde o aluno é preparado somente para fazer provas, com objetivo de melhores índices nas avaliações. Assim, 
tudo vira objeto a ser atingido, não se preocupando com o conhecimento, com a humanização. Mas Morin (2011) nos alerta:

Para a educação é necessário promover grande remembramento dos conhecimentos oriundos das ciências naturais, a fim de situar a condição humana, para colocar em evidência a multidimensionalidade e a complexidade humanas, bem como para integrar (na educação do futuro) a contribuição inestimável das humanidades, não somente a filosofia e a história, mas também a literatura, a poesia, as arte (MORIN, 2011, p. 44).

Quando se adota uma pedagogia que busca romper fragmentações, evidenciar situações problemas, proporcionar reflexões e que promova conhecimento crítico, contextualizado e interdisciplinar a todos envolvidos no processo é também promover um conhecimento humanizador. Estes elementos não se encontram presentes no caderno de Ciências da Natureza da BNCC, aliás o pensamento crítico é silenciado e a Educação ambiental crítica proposta na Introdução da BNCC é, por efeito de deslizamento, silenciada e paulatinamente substituída por termos relacionados com discursividades capitalistas e modernas. É necessário que as práticas pedagógicas, no contexto escolar, proporcionem reflexões e busquem a construção de novas atitudes e valores com os quais a comunidade escolar se reconheça como parte integrante do meio no qual está inserida.

\section{Considerações finais}

A Educação Ambiental na BNCC, que foi o foco desta pesquisa, encontra-se no rol daquelas disciplinas que serão abordadas segundo a organização de cada escola. A análise dos cadernos das Ciências da Natureza, no entanto, mostrou que o termo é citado tão timidamente que por si só passaria despercebido nos currículos escolares, por um processo de apagamento. A pesquisa evidencia que, como consequência disto, formaremos gerações de cidadãos cuja visão será a de que a natureza existe para ser dominada pelo ser humano, já que, o que se reforçará no inconsciente coletivo é que, se a escola não considera relevante o tema é porque o que se pratica hoje deve se perpetuar e que os recursos naturais são infindáveis. As implicações desta ação vão repercutir diretamente no trato que as novas gerações darão ao planeta. Exemplos desta tragédia estão ainda frescos nas nossas mentes.

O que se apreende dessa constatação é que, embora esta seja uma pesquisa inicialmente focada na constatação de um problema e suas implicações no campo das ciências naturais, o ponto de vista aqui defendido apoiou-se também em estudos da área de linguística, uma vez que o meio de materialização dos documentos é a língua. Assim, quando se fala em silenciamento remete-se aos estudos na área da Análise de Discurso, campo da linguística e da comunicação que analisa como ocorrem as construções ideológicas em um texto.

Assim, percorridos os caminhos das metodologias abordadas e da fundamentação teórica que conferem o arcabouço teórico ao texto, este artigo é finalizado com argumentos linguísticos dos textos de Eni Orlandi, no Brasil e pautados nos conceitos de Michel Pêcheux, cuja obra apresenta uma reflexão que faz pensar sobre o âmbito da "particularidade" da produção de sentidos. Para ele, se definem "contratos" linguísticos específicos que possibilitam aos sujeitos determinados dizeres e seu processo de produção do discurso para fundamentar a ideia de que o tema foi conscientemente relegado ao segundo plano. Nesta perspectiva, ocupamos posições na estrutura da formação social, posições de sujeito, patrão, diretor, político.

Esta ideia de posição de sujeito na estrutura social nos leva a estabelecer uma conexão com o texto de Eni Orlandi, em seu livro "As formas do silêncio", onde, entre outras constatações sobre o silêncio, a autora diz que algo que se configura como ameaça recebe no discurso um apagamento de sentidos, um silenciamento um não sentido.

A grande preocupação com o meio ambiente e a necessidade de se conversar sobre os riscos ambientais provocados pela relação desequilibrada do ser humano-natureza, vem sendo tema de debates contemporâneos. A escola, como instituição, pode proporcionar conhecimento e promover ações e reações e, assim, despertar o senso crítico ao promover uma Educação Ambiental Crítica (EAC). É preciso desempenhar a EA em sua totalidade para encaminhar ao entendimento sobre sua importância, reduzindo a visão fragmentada de mundo, além de romper paradigmas. Para isso, é preciso incorporar outras dimensões como a cultura, a política, a história entre outras, desempenhando assim uma EAC. 
Portanto, "Educação Ambiental antes de tudo é Educação", e fazer reflexões a respeito dos problemas ambientais desvinculadas da complexidade social, cultural, histórica, política, ideológica e econômica, resulta numa visão de mundo dualista, que dissocia as dimensões social e natural. A EAC, no contexto escolar, pode promover a quebra de paradigmas, posto que ela não se reduz somente ao meio ambiente, já que existe um conjunto conceitos que perpassam vários setores como o econômico, o social, o cultural, entre outros, buscando, assim, mais justiça, qualidade de vida, cidadania, igualdade e equidade.

Dessa forma, a escola é corresponsável pela promoção dessas mudanças, juntamente com o poder público, por meio da legislação na área ambiental. Mas muitos são os desafios e demandas no campo educacional que necessitam ser superados, como, por exemplo, uma formação adequada do professor, (re)definição do papel da escola na sociedade atual e uma melhor abordagem da Educação Ambiental no contexto escolar, formando, assim, uma sociedade com cidadãos comprometidos, conscientes e sensibilizados, sabedores do poder das ações individuais e coletivas para a qualidade de vida da natureza e do planeta, para as futuras gerações numa relação de envolvimento, de conexão e equilíbrio com a sua própria natureza. E a prática escolar com perspectiva da EAC exige do educando conhecimento da posição ocupada, pois, convém relembrar que a EAC não favorece a separação entre cultura-natureza. A questão que se coloca é saber a que sujeitos interessa que temas polêmicos sejam apagados dos currículos, a quem interessa a ausência de disciplinas críticas nos documentos escolares. Deixamos aqui a pergunta.

\section{Referências}

ACOSTA, A.; BREDA, T. O Bem Viver: uma oportunidade para imaginar outros mundos. São Paulo: Editora Elefante, 2016.

BRASIL. Base Nacional Comum Curricular. (BNCC). Brasília: Ministério da Educação, 2018. Disponível em: $<$ http://basenacionalcomum.mec.gov. br/images/BNCC_EI_EF_110518_versaofinal_site. pdf $>$

DIAMOND, J. Colapso: Como as sociedades escolhem o fracasso ou o sucesso. $[S$. l.]: Editora Record, 2005.

CARVALHO, I. C. M.; GRUN, M.; TRAJBER, R. Pensar o ambiente: bases filosóficas para a educação ambiental. Brasília: Organização das Nações Unidas Para Educação, a Ciência e a Cultura, 2006.

DUSSEL, E. Buen Vivir. [S. l.: s. n.], 2018. Vídeo do you Tube (41min10s). Disponível em: $<$ https:// www.youtube.com/ watch? $\mathrm{v}=\mathrm{DLIEm} 6 \mathrm{Smds} \&$ list $=$ FLmTAry68BsL1JvGajwcBYxA\&index $=863 \& \mathrm{ab}$ channel=C.Paizanni $>$

FERRARI, A. J. Nomes próprios e descrição: um estudo da descrição e do nome próprio a partir da análise das descrições presentes nos anúncios de fuga de escravos publicados nos jornais de Campinas entre 1870 e 1876. Tese (Doutorado em Linguística) - Instituto de Estudos da Linguagem, Universidade Estadual de Campinas, Campinas, 2008.

FERRARI, A. J. O silêncio da Dona Amélia. In: FONTANA, M. G. Z.; FERRARI, A. J. Mulheres em discurso: identificações de gênero e práticas de resistência. Campinas: Pontes, 2017. v. 1, p. 231-251.

GONÇALVES, C. W. P. Os (des) caminhos do meio ambiente. 13. ed. São Paulo: Contexto, 2005.

LOUREIRO, C. F. Trajetória e Fundamentos da Educação Ambiental. 4. ed. São Paulo: Cortez, 2012.

LOUREIRO, C. F.; TORRES, Juliana. Educação ambiental: Dialogando com Paulo Freire. 1. ed. São Paulo: Cortez Editora, 2014.

MORIN, E. Os sete saberes necessários à Educação do futuro. São Paulo: Cortez, 2011.

ORLANDI, E. P. Análise de Discurso: Princípios e Procedimentos. 12. ed. Campinas: Pontes, 2015.

ORLANDI, E. P. As formas do silêncio: no movimento dos sentidos. 6. ed. Campinas: UNICAMP, 2007.

QUIJANO, A. "Bem viver": entre o "desenvolvimento" e a "des/colonialidade" do poder. Revista da Faculdade de Direito da UFG, v. 37, n. 1, p. 46-57, 2013.

QUIJANO, A. Colonialidade do Poder e Classificação Social. In: SANTOS, B. S.; MENESES, M. P. Epistemologias do sul. Coimbra: Edições ALMEDINA, 2009. v. 1.

SANTOS, M. A Natureza do Espaço: Técnica e Tempo, Razão e Emoção. 4. ed. São Paulo: Edusp, 2006.

SILVA, T. D. Educação ambiental: a educação para o consumo na sociedade da informação. Linguagem em (Dis)curso, v. 11, n. 3, p. 563-584, 2012.

TOZONI-REIS, M. F. C.; MAIA, J. S. S. Educação ambiental a várias mãos: educação escolar, currículo e políticas públicas. 1. ed. Araraquara: Junqueira \& Marin, 2014. 